\title{
Assessment of gas cylinder vehicles adaptability for operation at low ambient temperature conditions
}

\author{
I. Anisimov, A. Ivanov, E. Chikishev, D. Chainikov \& L. Reznik \\ Tyumen State oil and Gas University, Russian Federation
}

\begin{abstract}
Currently, there is a slowdown in oil production, which contributes to higher prices for liquid motor fuel. In this regard, the next 60-70 years alternative of natural gas on transport won't be. In low ambient temperature conditions operation of cars on gas fuel becomes complicated, its consumption increases, and emissions of harmful substances change. In addition, a variety of vehicles in different ways adapted to the low ambient temperature.

Currently, both in Russia and abroad there are no mentioned works, the main aim of which is to establish the relationships of low temperature influence on fuel consumption and harmful substance emissions of vehicles. Also there are no works estimating adaptability level of gas cylinder vehicles during the work on compressed natural and liquefied oil gas for these operating conditions.

Assessment of gas cylinder vehicles adaptability levels to low ambient temperature operation conditions by fuel consumption and harmful substance emissions is the purpose of this paper.

A space-time approach to assessing vehicles adaptability levels for low ambient temperature was used. The work included the carrying out of theoretical operational, bench and control tests. Distribution of vehicles on adaptability levels for low ambient temperature operation conditions became the main results of research. On the basis of these results we can draw conclusions about what brands, models of vehicles, with which gas fuel supply system, during the work on what gas fuel (the compressed natural and liquefied petroleum gas) are more adapted for use in low ambient temperature from the point of view of changes of fuel consumption and of harmful substances emission in the exhaust gases.

Keywords: low ambient temperature conditions, adaptability, fuel consumption, harmful substances emissions.
\end{abstract}




\section{Introduction}

Currently in the liquid fuel prices (petrol, diesel) stable raising period the question of transport conversion to gas fuel becomes more and more actual. Analyzing the situation in the oil products market and realizing that oil reserves are limited, it is possible to draw a conclusion that in the nearest future there'll not be any alternative to gas fuel. Rolling stock operation on the fuel derived from crops, most likely can't be alternative to oil as it will cause a food prices boom and the use of this energy source type will be limited at the international level.

Before full-scale conversion to gas fuel there is certain time. But already now it is necessary to solve some problem issues which transport operating on gas comes across. For example, at transport operation in Russia much attention is paid to climatic factors. The cold climate zone occupies the largest part of our country territory - about $70 \%$ (central and northern parts of Russia, Western Siberia, Eastern Siberia and the Far East), therefore in considerable part of Russia the low ambient temperature prevail. Under these low temperature conditions, there appear difficulties when operating gas cylinder vehicles. When operating under these conditions fuel consumption changes. It is connected with the change of mixture formation and combustion processes. This change, in particular, leads to wrong correction of norms and normatives of technical operation, including - fuel consumption norms [1]. More objective correction of fuel consumption norms can be obtained if based on the adaptability of vehicles to low air temperatures conditions when operating on liquefied petroleum (LPG) and compressed natural gas (CNG ). This assessment will allow to reveal when operating which gas fuel vehicle is more adapted to the temperature change of the operation conditions.

It is also necessary to pay attention to change of harmful substances emissions in exhaust gases of vehicles. Changing the ambient air temperature affects the engine's combustion process, which in turn affects harmful substances emission. Due to intensive environmental pollution the question of vehicles emissions is very acute. To estimate how the harmful substances emission is changed at change of temperature conditions of the particular vehicle is possible by assessing its adaptability level $[2,3]$.

\section{Methodology}

The purpose of investigation is to estimate the vehicles adaptability operating on regular and gas fuel for low-temperature operation conditions by fuel consumption and harmful substances emissions in exhaust gases.

The object of research is the process of fuel consumption and harmful substances emissions in exhaust gases of gas cylinder vehicles change under low temperature operation conditions.

The subject of research is this process for the Russian vehicles of specific brands and models. 
As a subject of research the car GAZ-3110 with ZMZ - 406.2.10 engine, using petrol as a regular fuel converted to LPG and CNG was chosen.

The experiment was made in the conditions of Tyumen in 2005-2012 yrs. Range of air temperatures varied between $-39,6 \ldots+20^{\circ} \mathrm{C}$. Fuel economy of the car was estimated at even movement with constant speed of $90 \mathrm{~km} / \mathrm{h}$ on a direct gear. Running down distance $-10 \mathrm{~km}$.

Measurement of fuel consumption (petrol and LPG) was made by "topping up a tank (cylinder) to the full" method, and natural gas according to reference tables.

Change of harmful substances emissions in exhaust gases estimation experiment was carried out for the engine of the car at the load bank corresponding to European Driving Cycle UNECE. Change in emissions of CO, $\mathrm{CH}$ and $\mathrm{NOx}$ was determined in the experiment.

\section{Results and analysis}

The experiment allowed us to construct graphical dependences of temperature influence on fuel consumption (fig. 1).

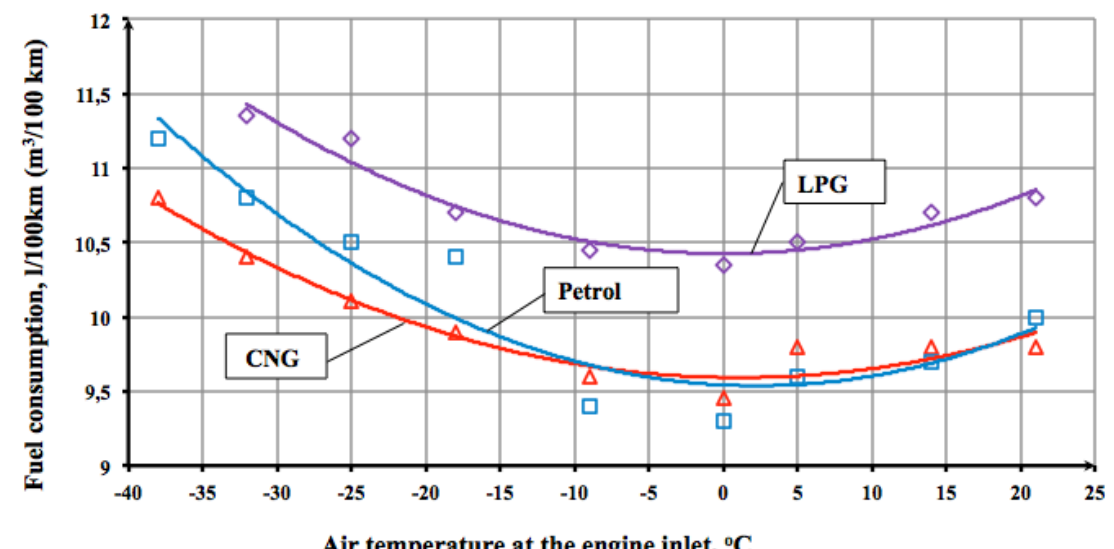

Figure 1: Influence of air temperature on fuel consumption during the operating on petrol, liquefied petroleum gas, and compressed natural gas.

Analyzing the dependencies it is possible to reveal that the car is less sensitive to air temperature change during the operation on compressed natural gas. Car operating on LPG at low temperatures has a greater impact on its fuel consumption. However the least adapted by climatic conditions is the car operating on petrol, in terms of fuel economy [4-6].

During the operation on petrol very important question is quality of fuel spray and providing its mixing with air to create a combustible mixture. At low temperatures the process of mixing is difficult because part of the petrol can 
settle, condense on the walls of the inlet manifold and on the combustion chamber in the filling stroke period. Thus, it is required more fuel for a unit of work production. During the operation on gas fuels the question of mixing is less important, because the gas is easily mixed up with air, doesn't settle on the walls of the inlet tract and burns more completely $[7,8]$. In the case of operation on LPG the problem appears to supply fuel into the engine cylinder. The filling process is provided by the pressure in the gas cylinder, but with air temperature decreasing this pressure is reduced due to the physical characteristics of gases (propane, butane) comprising liquefied petroleum gas. As experiment showed at air temperature minus $38^{\circ} \mathrm{C}$ it wasn't successful to provide functioning of the car on this type of fuel. Operating of vehicles on $\mathrm{CNG}$ facilitates car use on this fuel under negative air temperatures conditions [9]. This gas is more uniform by the structure, as well as gas from a cylinder is provided with high pressure under which gas is placed into a cylinder, instead of changing the aggregate state as in the case of LPG.

The graphic dependences in figure 1 are described in general by the following mathematical model:

$$
q=q_{o}+S_{q} \cdot\left(t-t_{o}\right)^{2}
$$

where:

$q_{o}-$ optimal fuel consumption, $\mathrm{kg} / \mathrm{h}$;

$S_{q}-$ sensitivity parameter to changes in air temperature at the engine inlet by fuel consumption, $1\left(\mathrm{~m}^{3}\right) /\left(100 \mathrm{~km} \cdot{ }^{\circ} \mathrm{C}^{2}\right)$;

$t_{o}-$ optimal ambient temperature, ${ }^{\circ} \mathrm{C}$;

$t-\quad$ actual ambient temperature, ${ }^{\circ} \mathrm{C}$.

Change of harmful substances emissions depending on the air temperature looks as follows (figs. 2-4).

From the presented graphic dependences it follows that the air temperature at the engine inlet significantly influences the volume content of $\mathrm{CO}, \mathrm{C}_{\mathrm{n}} \mathrm{H}_{\mathrm{m}}$ and NOx in the exhaust gases. It is explained by change in the composition of the fuel-air mixture and, respectively, by excess-air coefficient $\alpha$. With air temperature on the engine inlet decreasing, air density increases, and it leads to an increase of the excess-air coefficient $\alpha$.

When using petrol as fuel its considerable part comes to the cylinders in the liquid phase (drops and films), which leads to the deterioration in mixing compared with LPG use which comes into the engine as a gas phase.

The amount of harmful substances in exhaust gases after the conversion of engines to LPG power considerably decreases. The quantity of incomplete combustion products, such as carbon oxide and hydrocarbons in the exhaust gases decreases. At the same time the concentration of nitrogen oxides due to the lower temperature of engine operating cycle decreases a little. Gas fuel compared with petrol has wider limits of ignition. It allows US to lean the fuel mixture on the basic operational modes most effectively. 


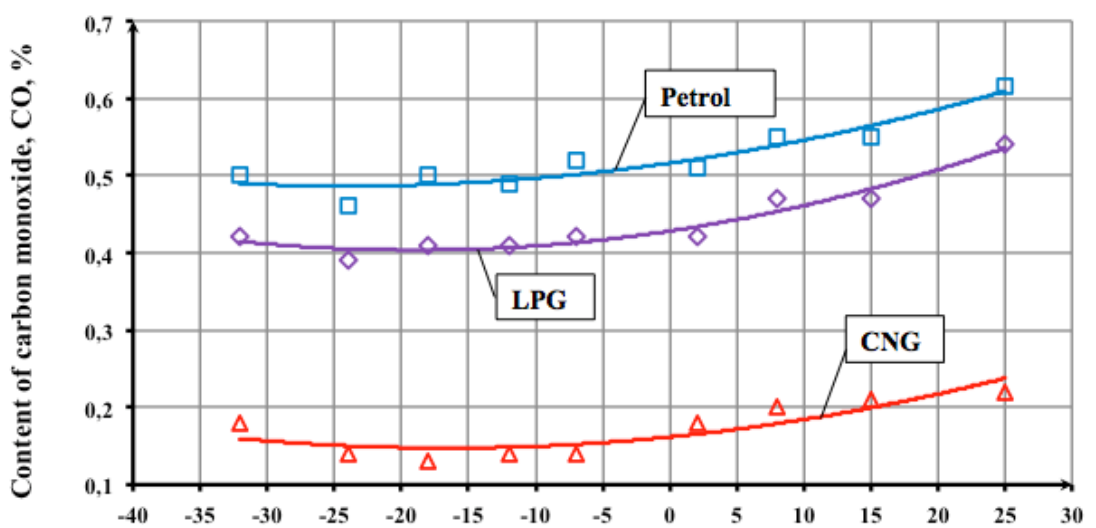

Air temperature at the engine inlet, ${ }^{\circ} \mathrm{C}$

Figure 2: Influence of air temperature on $\mathrm{CO}$ emissions during operation on petrol, liquefied petroleum gas and compressed natural gas at $\mathrm{P}=65 \mathrm{~kW}, \mathrm{n}=3000 \mathrm{~min}^{-1}$.

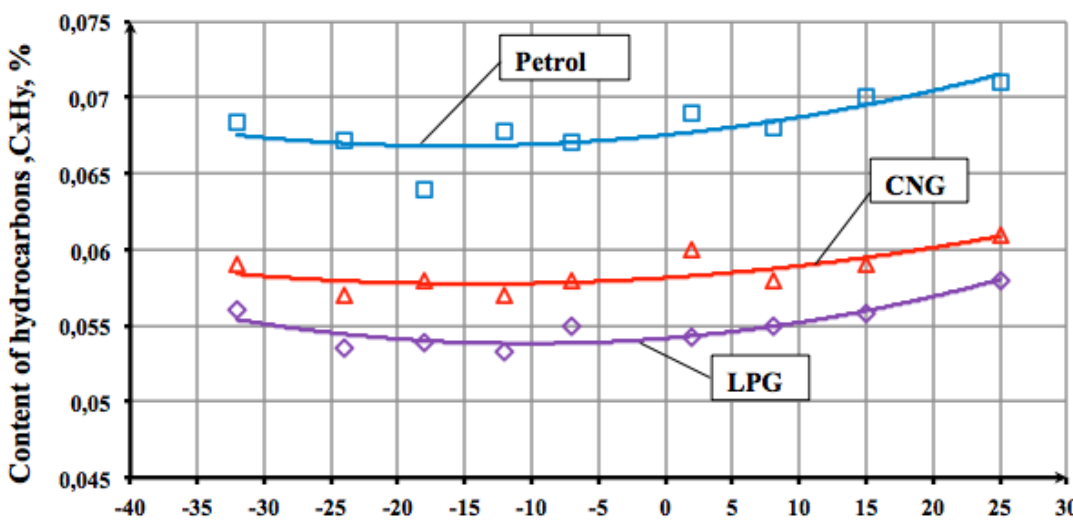

Air temperature at the engine inlet , ${ }^{\circ} \mathrm{C}$

Figure 3: Influence of air temperature on the emissions of $\mathrm{CH}$ during operation on petrol, liquefied petroleum gas and compressed natural gas at $\mathrm{P}=65 \mathrm{~kW}, \mathrm{n}=3000 \mathrm{~min}^{-1}$. 


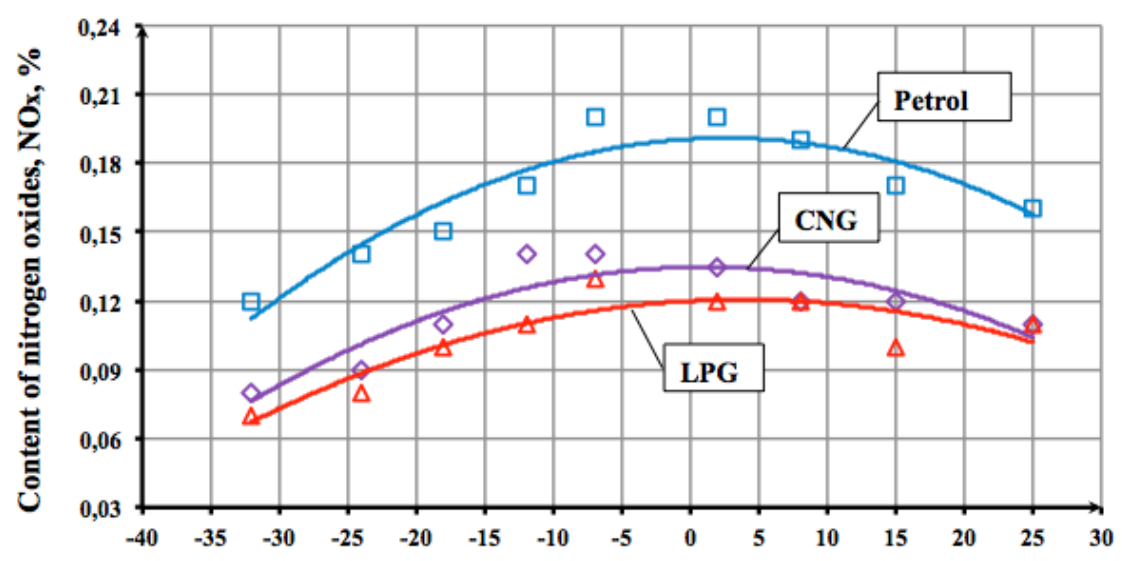

Air temperature at the engine inlet, ${ }^{\circ} \mathrm{C}$

Figure 4: Influence of air temperature on NOx emissions during operation on petrol, liquefied petroleum gas and compressed natural gas at $\mathrm{P}=65 \mathrm{~kW}, \mathrm{n}=3000 \mathrm{~min}^{-1}$.

The content of carbon monoxide in the exhaust gases reaches its minimum in the range of air temperature at the engine inlet $\mathrm{ZMZ}-4062.10$ from -20 to $+5^{\circ} \mathrm{C}$ during engine operation on gasoline, and from -27 to $0^{\circ} \mathrm{C}$ during operation on LPG, depending on the speed and load modes.

The content of hydrocarbons in the exhaust gases depending on the air temperature at the engine inlet is changed insufficiently. When air temperature at the engine inlet decreases the volume content of nitrogen oxides in the exhaust gases decrease, when operating both on petrol and LPG.

The content of hydrocarbons in the exhaust gases reaches minimum values in the range of temperatures from -25 to $+5^{\circ} \mathrm{C}$. The dependence of volume content of nitrogen oxides in the exhaust gases on the air temperature at the engine inlet differs by the mode of behavior of $\mathrm{CO}$ and $\mathrm{C}_{\mathrm{n}} \mathrm{H}_{\mathrm{m}}$ dependencies. The content of $\mathrm{NOx}$ in the exhaust gases reaches its maximum value at the air temperature at the engine inlet from -5 to $+25^{\circ} \mathrm{C}$ on petrol and $\mathrm{CNG}$, depending on the mode of engine operation. Deviation of air temperature value from the optimal one leads to the change in the content of harmful substances in the exhaust gases. This is explained by the change of the air-fuel mixture composition.

In particular the biggest decrease is in emissions of $\mathrm{CO}-$ by $60-75 \%$. Reduction of NOx emissions is within $25-50 \%$, and $\mathrm{C}_{n} \mathrm{H}_{m}-10-25 \%$. CNG compared with petrol has wider limits of ignition, it allows to lean the fuel mixture on the basic operational modes most effectively.

Revealed dependences in general can be described by the following regularities.

$$
X_{C O}=X_{O}^{C O}+S_{h s}^{C O} \cdot\left(t-t_{o}^{C O}\right)^{2}
$$




$$
\begin{aligned}
& X_{C H}=X_{O}^{C H}+S_{h s}^{C H} \cdot\left(t-t_{o}^{C H}\right)^{2}, \\
& X_{N O}=X_{O}^{N O}-S_{h s}^{N O} \cdot\left(t-t_{o}^{N O}\right)^{2},
\end{aligned}
$$

where:

$$
\begin{aligned}
& X_{O}^{C O}, X_{O}^{C H}, X_{O}^{N O}-\quad \text { optimal content of respectively, } \mathrm{CO}, \mathrm{C}_{\mathrm{n}} \mathrm{H}_{\mathrm{m}}, \mathrm{NOx}, \% \text {; } \\
& S_{h s}^{C O}, S_{h s}^{C H}, S_{h s}^{N O}-\quad \text { sensitivity parameters to the air temperature changes } \\
& \text { by the content of respectively, } \mathrm{CO}, \mathrm{C}_{\mathrm{n}} \mathrm{H}_{\mathrm{m}}, \mathrm{NOx} \text {, } \\
& \% /{ }^{\circ} \mathrm{C} \text {; } \\
& t_{o}^{C O}, t_{o}^{C H}, t_{o}^{N O}-\quad \text { optimum air temperature at the engine inlet by the } \\
& \text { content of } \mathrm{CO}, \mathrm{C}_{\mathrm{n}} \mathrm{H}_{\mathrm{m}}, \mathrm{NOx},{ }^{\circ} \mathrm{C} \text {. }
\end{aligned}
$$

Based on the adaptability theory [10-12], it is possible to determine the level of vehicles adaptability at operation on different fuels under negative air temperatures. Vehicle adaptability means its characteristic to keep the values of quality measures and efficiency measures on their nominal level while there is a deviation of operation conditions from standard ones. As standard temperature conditions air temperature equal to $+25^{\circ} \mathrm{C}$ is accepted. To quantify the adaptability of vehicles to operation under low temperature conditions the adaptability coefficient is used. It shows how many times the value of an indicator of quality and efficiency in the given conditions differs from base value. Theoretical borders of adaptability coefficient is from 0 to 1 . The closer the adaptability coefficient to 1 the better the adaptability. Thus, vehicle adaptability (A) to change of ambient temperature $\left(t_{a}\right)$ can be defined by the following formula [12]:

$$
A=\frac{q_{H}}{q_{\phi}},
$$

where:

$q_{n} \quad-$ nominal fuel consumption value at standard conditions, $1 / 100 \mathrm{~km}$ $\left(\mathrm{m}^{3} / 100 \mathrm{~km}\right)$;

$q_{a} \quad-$ actual fuel consumption in the given conditions, $1 / 100 \mathrm{~km}$ $\left(\mathrm{m}^{3} / 100 \mathrm{~km}\right)$.

Having data of fuel consumption values at a specific ambient temperature it is possible to construct a graphic dependence of the adaptability coefficient changes under different values of air temperature (fig. 5).

Analyzing graphic dependences and mathematical models of air temperature influence on the adaptability coefficient change it is possible to confirm the hypothesis that during the operation on CNG and LPG car is better adapted to changing of temperature conditions by fuel consumption, in relation to its operation on petrol. 


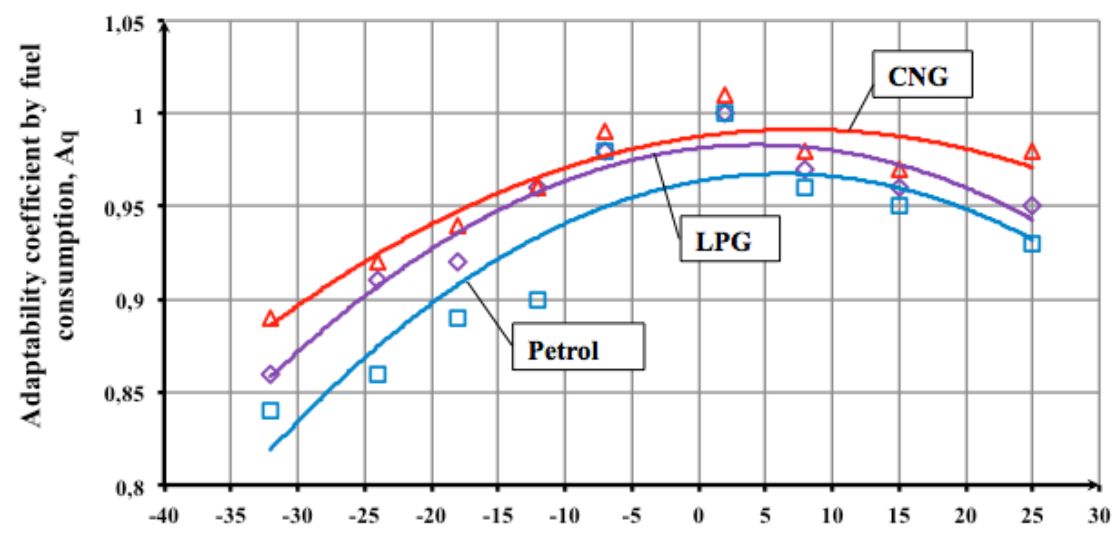

Air temperature at the engine inlet,${ }^{\circ} \mathrm{C}$

Figure 5: Influence of air temperature on the adaptability coefficient by fuel consumption when operating on petrol, LPG and CNG.

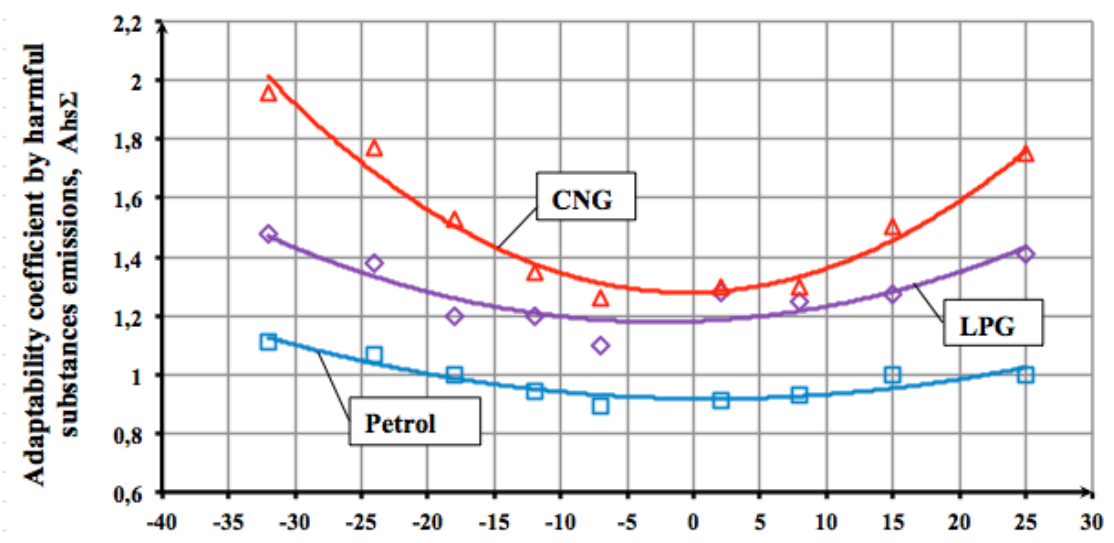

Air temperature at the engine inlet , ${ }^{\circ} \mathrm{C}$

Figure 6: Influence of air temperature on the adaptability coefficient by harmful substances emissions when operating on petrol, LPG and CNG.

The graphic dependences given above are described by the following mathematical model.

$$
A_{q}=A_{o}+S_{t}^{A} \cdot\left(t-t_{o}\right)^{2}
$$

where:

$A_{O} \quad-\quad$ adaptability coefficient under $0^{\circ} \mathrm{C}$ ambient temperature; 
$S_{t}^{A} \quad-\quad$ sensitivity parameter to ambient temperature change by adaptability coefficient, $1 /{ }^{\circ} \mathrm{C}^{2}$.

On the basis of harmful substances emissions in exhaust gases values under concrete ambient temperature it is possible to construct graphic dependence of adaptability coefficient change under different values of the air temperature (fig. 6).

Excess-air coefficient $\alpha$ is the quantitative characteristic of the combustible mixture composition. Based on the available dependencies of $\alpha$ influence on changing of the volume content of $\mathrm{CO}, \mathrm{C}_{\mathrm{n}} \mathrm{H}_{\mathrm{m}}$, NOx and dependencies of temperature influence on $\alpha$, the content of harmful substances in exhaust gases varies both with decreasing and increasing the air temperature at the engine inlet compared to the nominal value $[7,13]$.

The revealed dependences are mathematically described by the following model.

$$
A_{h s}^{\Sigma}=A_{o}+S_{t}^{A} \cdot\left(t-t_{o}\right)^{2}
$$

where: $A_{h s}^{\Sigma}$-total adaptability coefficient of vehicles to low-temperature operation conditions by harmful substances emissions in the exhaust gases.

Applying the theory of structural analogies described in $[14,15]$ it is possible to determine vehicles adaptability levels to low-temperature operation conditions by fuel consumption and harmful substances emissions in exhaust gases. In the backbone of a theory the analysis of vehicle engine room configuration, the feature of air inlet into the engine, the extent of the engine room warming and other factors are established.

Cars adaptability to low-temperature operation conditions by fuel consumption can be estimated using the adaptability levels (table 1).

Cars adaptability to low-temperature operation conditions by harmful substances emissions in exhaust gases can be estimated using the adaptability levels too (table 2).

Table 1: Cars adaptability to low-temperature operation conditions by fuel consumption.

\begin{tabular}{|c|c|c|c|}
\hline \multirow{2}{*}{$\begin{array}{c}\text { Adaptability } \\
\text { level }\end{array}$} & \multicolumn{3}{|c|}{ Fuel type } \\
\hline & Petrol & $\mathrm{CNG}$ & LPG \\
\hline High & $\begin{array}{c}\text { Lada Kalina, Lada } \\
\text { Priora }\end{array}$ & $\begin{array}{c}\text { GAZ-3110, Lada } \\
\text { Kalina, Lada Priora, } \\
\text { Lada Samara }\end{array}$ & $\begin{array}{c}\text { Lada Kalina, Lada } \\
\text { Priora, Lada } \\
\text { Samara }\end{array}$ \\
\hline Middle & $\begin{array}{c}\text { GAZ-3110, Lada } \\
\text { Samara, UAZ Patriot }\end{array}$ & UAZ Patriot & $\begin{array}{c}\text { GAZ-3110, UAZ } \\
\text { Patriot }\end{array}$ \\
\hline Low & $\begin{array}{l}\text { UAZ Hanter, VAZ- } \\
2107\end{array}$ & $\begin{array}{c}\text { UAZ Hanter, VAZ- } \\
2107\end{array}$ & $\begin{array}{l}\text { UAZ Hanter, } \\
\text { VAZ-2107 }\end{array}$ \\
\hline
\end{tabular}


694 Energy Production and Management in the 21st Century, Vol. 1

Table 2: Cars adaptability to low-temperature operation conditions by harmful substances emissions in exhaust gases.

\begin{tabular}{|c|c|c|c|}
\hline \multirow{2}{*}{$\begin{array}{c}\text { Adaptability } \\
\text { level }\end{array}$} & Petrol & Fuel type \\
\cline { 2 - 4 } High & $\begin{array}{c}\text { Lada Kalina, Lada } \\
\text { Priora }\end{array}$ & $\begin{array}{c}\text { GAZ-3110, Lada } \\
\text { Kalina, Lada Priora, } \\
\text { Lada Samara }\end{array}$ & $\begin{array}{c}\text { GAZ-3110, Lada } \\
\text { Kalina, Lada } \\
\text { Priora, }\end{array}$ \\
\hline Middle & GAZ-3110, Lada & UAZ Patriot & $\begin{array}{c}\text { Lada Samara, } \\
\text { UAZ Patriot }\end{array}$ \\
\hline Low & UAZ Hara, UAZ Patriot & 2107 & $\begin{array}{c}\text { UAZ Hanter, } \\
\text { VAZ-2107 }\end{array}$ \\
\hline
\end{tabular}

\section{Conclusions}

1. Influence of low-temperature operation conditions on fuel consumption and harmful substances emissions in exhaust gases of various vehicles makes and models. It is revealed that this influence is described by quadratic mathematical models

2. Adaptability of these vehicles to low-temperature operation conditions by fuel consumption and harmful substances emissions in vehicles exhaust gases is determined. This dependence is described by quadratic mathematical models.

3. Adaptability levels of vehicles to low-temperature operation conditions by fuel consumption harmful substances emissions in vehicles exhaust gases are determined. The engine room configuration and feature of air inlet into the engine are influence on adaptability level.

\section{References}

[1] Reznik L.G., Vilenskiyi L.I., Winter fuel economy, Motor transport: Moscow, pp. 38-39, 1981.

[2] Magaril E.R., Reznik L.G., Emissions integral estimate, Automotive industry: Moscow, p. 9, 1998.

[3] Karnaukhov N.N., Reznik L.G., Manyashin A.W. The influence of automobiles motion unevenness on harmful substances emission, Advances in transport, pp. 553-560, 2002.

[4] Pevnev N.G., Technical operation of natural gas vehicles, SibADI: Omsk,. 182 p., 1993.

[5] Chikishev E.M., Assessment of natural gas vehicles adaptability to lowtemperature operation conditions by fuel consumption and toxicity of exhaust gases, Diss . ... cand. of tehn. sciences, TSOGU: Tyumen, 189 p., 2011.

[6] Ivanov A.S., Gas-diesel vehicles adaptability to low-temperature operation conditions and weight of cargo by fuel consumption and toxicity 
of exhaust gases, Diss .... cand. of tehn. sciences, TSOGU: Tyumen, 155 p., 2011.

[7] Gnatyuk E.V., Pevnev N.G., Investigation of the explosion stability of liquefied gases in an it unit, Chemistry and technology of fuels and oils Volume: 6 Number: 3, pp. 216-219, 1970.

[8] Gnatyuk E.V., Pevnev N.G., Method of determining knock intensity in the study of the antiknock rating of fuels, Chemistry and Technology of Fuels and Oils, Volume: 7 Number: 3, pp. 219-221, 1971.

[9] Yerokhov V.I., Gas-cylinder cars. Design, transferring, operation, repair., Akademkniga: Moskow, p. 238, 2003.

[10] Karnaukhov N.N., Reznik L.G., The differentiated correction of charge for air pollution, Advances in transport, Volume: 16, pp. 701-705, 2004.

[11] Reznik L.G., Vehicles operation conditions severity index, Oil and Gas: Tyumen, № 1, p. 112, 2000.

[12] Chainikov D.A., Estimation of car adaptability to cargo weight concerning fuel consumption, Urals Transport: Ekaterinburg, №3, pp. 9294, 2008.

[13] Anisimov I.A., Multicriteria analysis of gas-diesel vehicles operation at low temperatures, Urals Transport: Ekaterinburg, № 2, pp. 103-104, 2009.

[14] Chumlyakov K.S., Assessment algorithm of vehicles adaptability to severe low-temperature operation conditions by fuel consumption, Urals Transport: Ekaterinburg, № 4, pp. 95-96, 2008.

[15] Chumlyakov K.S., Identification of vehicles adaptability levels to severe low-temperature operation conditions, Urals Transport: Ekaterinburg, №3, pp. 97-99, 2008. 